\title{
Community Knowledge and Perceptions about Buruli Ulcers in Obom Sub-District of the Ga South Municipality in the Greater Accra Region of Ghana
}

\author{
Eric Koka \\ Department of Sociology and Anthropology, University of Cape Coast, Cape Coast, Ghana \\ Email: ekoka@ucc.edu.gh
}

How to cite this paper: Koka, E. (2018). Community Knowledge and Perceptions about Buruli Ulcers in Obom Sub-District of the Ga South Municipality in the Greater Accra Region of Ghana. Advances in Applied Sociology, 8, 621-645.

https://doi.org/10.4236/aasoci.2018.89037

Received: August 23, 2018

Accepted: September 17, 2018

Published: September 20, 2018

Copyright $\odot 2018$ by author and Scientific Research Publishing Inc. This work is licensed under the Creative Commons Attribution International License (CC BY 4.0).

http://creativecommons.org/licenses/by/4.0/

(c) (i) Open Access

\begin{abstract}
Community knowledge and perceptions of the cause and consequently the appropriate measure to remedy an ailment determine whom people turn to for advice, help, information and treatment when bogged down with a disease. The role that community plays in the etiology, explanation, prognosis and treatment seeking behaviour cannot be underscored, because it provides in-depth information on the burden of the disease, the local understanding of the causes of the disease and therefore its management. The purpose of the study was to describe community knowledge and perceptions about Buruli ulcer (BU) and how to prevent Buruli ulcer in the Obom sub-district of Ghana. Survey questionnaire was used as an instrument for data collection to solicit information on community knowledge and perceptions of Buruli ulcer in the communities. In selecting respondents for the community survey, systematic sampling was used to select 300 respondents for the study. The study revealed a high level of knowledge about Buruli ulcer in the selected endemic communities. However, Buruli ulcer patients were perceived as people who have been bewitched (36.7\%). Others (21\%) blamed them as people who did not take good care of themselves while another $11.1 \%$ saw Buruli ulcer infected people as having normal wounds. Findings therefore show that although there was a high knowledge of signs and symptoms of Buruli ulcer among community members in the Obom sub-district, their understandings and interpretations of its causative factors varied from those of the biomedical understandings. Based on the results of the study, it is recommended that community outreach and education on the treatment and management of Buruli ulcer should be continued on a sustainable basis in the endemic communities.
\end{abstract}




\section{Keywords}

Buruli Ulcer, Knowledge, Perceptions, Reactions

\section{Background}

Buruli ulcer is a devastating infectious disease caused by Mycobacterium ulcerans. It is named after Buruli County (now called Nakasongola District) located near the Nile River in Uganda, where in 1961 the first large number of cases was reported (WHO, 2009). Mycobacterium ulcerans infection was first described in 1987 by Sir Alfred Cook, a missionary doctor in the Buruli County in Uganda (WHO, 2000). However, there has been no reported incidence of the disease in Nakasongola District since the 1980s. The causative organism is from the family of bacteria which causes tuberculosis and leprosy but Buruli ulcer has received less attention than these diseases (WHO, 2009; Kargbo-Labour, 2010). The exact mode of transmission is still under investigation. However, some patients state that lesions develop at the site of antecedent trauma. Research suggests that in Africa, some aquatic insects of the order Hemiptera (Naucoridae and Belostomatidae) can harbour M. ulcerans in their salivary glands and transmit the disease to experimental animals. More recent data from Australia suggest that salt marsh mosquitoes test positive for $M$. ulcerans DNA, although transmission by this type of mosquito has not been established. Further research is in progress to establish the exact role of insects and other factors in the transmission of the disease to humans. If confirmed, Buruli ulcer will be the only known mycobacterial disease to be transmitted by insects (WHO, 2009; Kargbo-Labour, 2010). The natural reservoir and mode of transmission of the infection remain largely obscure and might differ between endemic foci around the world. However, skin injury and insect bites have been proposed as modes of transmission (Nienhuis et al., 2010).

\section{Rationale}

A number of studies on Buruli ulcer have discussed socio-cultural aspects of the disease, including perceptions on causality, attitudes toward treatment and the economic burden of hospitalised patients (Asiedu \& Etuaful, 1998; Adamba \& Owus, 2011; Ahorlu et al., 2013; Koka et al., 2016). However, most of these studies tend to focus on Buruli ulcer related beliefs, perceptions and practices of the affected people as well as the socio-economic cost of the disease and how these have affected early case detection/diagnosis and treatment seeking behaviour and other control activities negatively. Most of these studies recommended the need for Information, Education and Communication (IEC) intervention to encourage early case detection and treatment with the assumption that once people gain knowledge they would take the appropriate action to access treatment early. In this direction, Ackumey et al. (2011) stated that intensifying health education 
and surveillance will create awareness and encourage early treatment. However, it has been argued that "all over the world those who do not comply are those least able to comply", (Paul, 1999) social science studies therefore, need to go beyond the description of existing problem and believing that health education would improve treatment seeking and adherence for Buruli ulcer treatment.

Studies have shown that, the community perception and knowledge about the disease have a negative impact on the health-seeking behaviour of patients. For this reason, all information on the socio-cultural factors (perception, knowledge and culture of wounds about the disease) are highly relevant for a better understanding of the disease as a whole and to serve as a useful material for future research and reference for policy makers, government and non-governmental institutions, world bodies such as the World Health Organisation (WHO) and the Centre for Disease Control and Prevention. The issues raised above informed the choice of the study titled; Community Knowledge and Perceptions about Buruli Ulcers in Obom sub-district of the Ga South Municipality in the Greater Accra Region of Ghana.

\section{Objectives}

The goal of this study was to describe community knowledge and perceptions about Buruli ulcer. Specifically, the study was designed to examine community understanding and reactions towards Buruli ulcer disease and the infected and how it can be prevented.

\section{Methods}

\section{Study Area}

The study took place in the Obom sub-district of the Ga South Municipality. The Ga South Municipality was carved from the then Ga West District in November 2007. The Municipality was established by Legislative Instrument 1987 in 2007 with the capital at Mallam. The Ga South (Weija) Municipal Area lies within Latitude 5 degree $48^{\prime}$ North and within Longitudes 0o 8' East and 0o 3' west. It has total land coverage of approximately $517.2 \mathrm{sq} . \mathrm{km}$. It shares boundaries with Accra Metropolitan Area to the South-East, Ga West to the East, Akwapim South to the North-East, West Akim to the North, Awutu Senya to the West, Gomoa to the South-West and the Gulf of Guinea to the South (Ghana Statistical Service, 2010). The three main languages spoken by community members are Ga, Akan and Ewe.

According to the extract from the 2010 National Population and Housing Census, the total population of the district is approximately 485,643 made up of 237, 558 (48.9\%) males and 248,085 (51.1\%) females. The high population size is due to the Municipality's closeness to the capital city Accra, making it home for many workers. According to the 2010 census, there are about 362 communities spread in the urban, peri-urban and rural areas of the Municipality. The coastal and the central portion of the Municipality have very dense population while the 
communities in the Northern section are sparely populated and scattered (Ghana Statistical Service, 2010).

Obom, a sub-district in the Ga-South municipality is located 15 kilometres to the north-east of Amasaman the district capital of Ga West Municipality. The Eastern part of the sub-district consists of low hills, interspersed with plains in the central parts. The river Densu, the largest water body in the district, runs through the sub-district. Other water bodies, which are tributaries of the Densu, are Adeiso, Honi and Ponpon rivers. There are also small ponds and seasonal streams. In addition, numerous surface water bodies have sprung up in the wake of extensive sand-winning activities to supply the building industry in the sub-district and the neighbouring Accra metropolis with sand. These water bodies are significant for economic activities such as fishing and farming as well as disease causation. Water-related diseases such as Buruli ulcer, schistosomiasis and malaria are endemic in the sub-district $(\mathrm{MoH}, 2012)$.

Apart from the two main health facilities (one in Obom, the sub-district capital and the other in Amasaman, the district capital of Ga West Municipality) that are accessible to residents in the sub-district, there are private clinics and maternity homes in the sub-district, some of which are at Mayra, Kojo Ashong, Domeabra, Oduman and Jei-Krodua. These facilities complement the efforts of the sub-district public health delivery, which could not reach majority of the people due to poor access and coverage. There are other decentralised health facilities (CHPS compounds) at Ashalagya, Balagono, Hobor and Kofikwei providing primary health care services to the populations that they serve. Owing to the poor condition of roads, the scarcity of means of transport and the fact that most communities are quite far from health facilities, access to health care is a major problem in the sub-district. The majority therefore utilise home treatment either home-made herbal treatment or over the counter medications usually bought from shops and itinerary vendors to manage ailments as a first line of action (MoH, 2012).

\section{Target Population and Sampling}

The population for the study included community members, Buruli ulcer patients and their caregivers and former Buruli ulcer patients in the Obom Sub-district of the Ga south Municipality. Survey questionnaires were used to collect data from the sampled community respondents.In selecting respondents for the community survey, systematic sampling was used to select compounds of potential respondents. The compounds were listed in the eleven most Buruli ulcer endemic communities. Using the procedure for generating compounds systematically, the compounds were selected in all the eleven communities for the survey. Thus, there were 2203 compounds in all eleven communities. Hence, 2203 was divided by the sample size of 300 given 7 . Thus every $7^{\text {th }}$ compound was visited for the study. In a given compound, two respondents were interviewed. However, in a compound where there were more than two adults, a 
simple random sampling (where yes or no was written on pieces of paper and tossed for the potential respondents) was used to select two respondents for the survey. The inclusion criteria for the survey was adults who were 18 years and above in a given compound. The estimated population for the eleven communities was 16,600 .

Using Epi-Info 7 software, with a population size of 16,600, the sample size of 242 was generated for the community survey. However, to make up for contingencies and nonresponse, questionnaires were administered to 300 respondents (Appendix).

\section{Study Design and Data Collection}

This was a descriptive study designed to determine community knowledge and perceptions about Buruli ulcer disease in the Ga South municipality. Survey questionnaire interviews were conducted with 300 community respondents in three major languages ( $\mathrm{Ga}$, Akan and Ewe) in the Obom sub-district of the Ga South municipality. The author designed the questionnaire in Appendix for the study. Before the main data collection, the survey questionnaire was pre-tested at Kojo Ashong; a community which is not part of the Obom sub-district. In all, thirty (30) community members were randomly selected and interviewed. This enabled the researcher to validate the tools prior to the main data collection. The data collection instruments after the pre-test, had to be modified to take care of some inconsistencies and difficulty in translations. The questionnaire contained five (5) main items or themes as; demographic information, basic health information of the study communities, community knowledge of Buruli ulcer signs and symptoms, community perceptions about Buruli ulcers and health seeking behaviour for Buruli ulcer and how to prevent Buruli ulcer in the communities as a sub-theme. However, for the purposes of this paper, results reflected demographic data, community knowledge and perceptions of Buruli ulcer and how it can be prevented (Appendix).

All questionnaires were self-administered to study participants by trained research assistants who were proficient in the local language.

\section{Data Analysis}

Epi-Info 7 was used to analyse the data. Basic statistical analyses of variables of interest were done by performing tabulations and cross-tabulations. The relevant tabulations yielded frequencies which were used to describe the basic summaries of the variables. The cross tabulations allowed for comparison between variables. Chi-squares and P-values were obtained for testing the associations between variables. The $\mathrm{p}$-value of $<0.05$ was considered significant.

\section{Ethical Review}

The Institutional Review Board of the Noguchi Memorial Institute for Medical Research, University of Ghana reviewed the study. The following ethical consid- 
erations were followed:

Ethical principles of anonymity, confidentiality, and rights of withdrawal were ensured among participants (Buruli ulcer coordinators and patients, and all other respondents). Research participants were informed about the objectives, methods and what was expected of them by clarifying their roles in the study to them. It was made clear to participants that their participation in the study was voluntary and refusal to take part would not affect their access to services offered by the health facility. No form of inducement was used to entice participants to partake in the study. However, refreshment and transportation was provided after interviews. To help protect the identity of patients and prevent questioning by community members, both the questionnaire administration and individual interviews were held within an environment devoid of many people, which were largely chosen by respondents. To ensure participants' right, an informed consent (both oral and written) was obtained from them before conducting the interview.

\section{Results}

\section{Demographic Profile of Respondents}

Table 1 shows the demographic profile of respondents. Out of the 300 respondents, $54 \%$ were females and $46 \%$ were males. The age distributions indicated that the majority (35.7\%) of the respondents were between 41 to 50 years old. Majority (51.7\%) of the respondents had no formal education. The population was dominated by the Ga ethnic group (55.7\%); $9.3 \%$ of the respondents were Akans. With regard to religion, the majority (75\%) of the respondents said they were Christians. Further analysis of the demographic data revealed that majority $(64.3 \%)$ of the respondents was engaged in trading/businesses of all kinds (Table 1).

\section{Knowledge of Buruli Ulcers}

Findings in Table 2 revealed a high level of knowledge about Buruli ulcer in the selected endemic communities. This revelation came to light when respondents were asked whether they heard of the disease that causes wounds, nodules, plaque etc. Out of the 300 respondents, 286 (95.3\%) said they had heard of Buruli ulcer (Table 2).

The subsequent question about its local name established the fact that local names of the disease vary by the local languages spoken by respondents. The dominant ethnic group (the Ga), has three local names for the disease and these are "helagbonyo", "abuagbonyo" and "odontihela". The Ewe call it "detsifudor", "abivordi", "abimakumaku" and the Akans call it "abuabone", "asawakuro" and "kisikuro" (Table 2).

It is important to know that the various local names for Buruli ulcer reported by all the ethnic groups have common meanings and interpretations. For example, the Ga people call the disease "Odontihela", the Ewe call it "Detsifudor" and 
Table 1. Demographic profile of survey respondents.

\begin{tabular}{|c|c|c|}
\hline Characteristics & $\begin{array}{c}\text { Frequency } \\
\mathrm{N}=\mathbf{3 0 0}\end{array}$ & Percentage \\
\hline \multicolumn{3}{|c|}{ Sex } \\
\hline Female & 162 & 54.0 \\
\hline Male & 138 & 46.0 \\
\hline \multicolumn{3}{|c|}{ Age } \\
\hline 20 and Below & 6 & 2.0 \\
\hline $21-30$ & 37 & 12.3 \\
\hline $31-40$ & 61 & 20.3 \\
\hline $41-50$ & 107 & 35.7 \\
\hline $51-60$ & 61 & 20.3 \\
\hline 61 and Above & 28 & 9.3 \\
\hline \multicolumn{3}{|c|}{ Education } \\
\hline No Education & 155 & 51.7 \\
\hline Junior High School & 35 & 11.7 \\
\hline Primary & 90 & 30.0 \\
\hline Senior High School & 17 & 5.7 \\
\hline Tertiary & 2 & 0.7 \\
\hline Vocational/Technical & 1 & 0.2 \\
\hline \multicolumn{3}{|c|}{ Ethnic group } \\
\hline $\mathrm{Ga}$ & 167 & 55.7 \\
\hline Ewe & 82 & 27.3 \\
\hline Akan & 28 & 9.3 \\
\hline Guan & 18 & 6.0 \\
\hline Other & 5 & 1.7 \\
\hline \multicolumn{3}{|c|}{ Religion } \\
\hline Christianity & 225 & 75.0 \\
\hline Islam & 51 & 17.0 \\
\hline Traditional & 20 & 6.7 \\
\hline No Religion & 4 & 1.3 \\
\hline \multicolumn{3}{|c|}{ Occupation } \\
\hline Trade/Business & 193 & 64.3 \\
\hline Farming & 55 & 18.3 \\
\hline Casual Labour/Sand Winning & 16 & 5.3 \\
\hline Fishing & 16 & 5.3 \\
\hline Other & 9 & 3.1 \\
\hline Farming + Fishing & 6 & 2.1 \\
\hline Unemployed & 4 & 1.3 \\
\hline Official Employee & 1 & 0.3 \\
\hline
\end{tabular}


Table 2. Knowledge of Buruli ulcers.

\begin{tabular}{|c|c|c|}
\hline Characteristics & $\begin{array}{c}\text { Frequency } \\
\mathrm{N}=\mathbf{3 0 0}\end{array}$ & Percentage \\
\hline \multicolumn{3}{|l|}{ Knowledge of BU (Nodule, Plaque, etc.) } \\
\hline Yes & 286 & 95.3 \\
\hline \multicolumn{3}{|l|}{ Local Names } \\
\hline Aboagbonyo/OdontiHela (Ga) & 200 & 70.0 \\
\hline Detsifudor (Ewe) & 60 & 21.0 \\
\hline Asawa Kuro/Kisi Kuro (Akan) & 26 & 9.0 \\
\hline \multicolumn{3}{|l|}{ Sources of Information } \\
\hline People in the community & 172 & 60.1 \\
\hline Seen some myself/Victim & 74 & 25.8 \\
\hline Media & 18 & 6.3 \\
\hline Hospital & 13 & 4.6 \\
\hline Rumour & 9 & 3.2 \\
\hline \multicolumn{3}{|l|}{ Reasons for the names } \\
\hline Because of the Odonti/Asawa (Cotton) in it & 151 & 52.8 \\
\hline It's a bad disease & 47 & 16.4 \\
\hline That is how our people call it & 46 & 16.1 \\
\hline I don't know & 27 & 9.4 \\
\hline It doesn't heal quick & 15 & 5.3 \\
\hline
\end{tabular}

Footnote: The following have been re-categorised for chi-square analysis: Age: $10-40=104$ (34.67\%), 41 and above $=196(65.33 \%)$. Education: No education $=155(51.67 \%)$, Primary and above $=145(48.33 \%)$.

the Akan call it "Asawakuro", and all these could be translated to mean "cotton wool disease". The Ewe call a chronic wound "abimakumaku" meaning a never healing wound whiles the Akan call it "kisikuro" to mean the same thing while the Ga call it "helagbonyo" meaning a large wound. These local names give credence to the fact that Buruli ulcer is a chronic disease, which takes a long time to heal.

To confirm their knowledge about the disease, respondents were asked where they got to know about the disease and its local names, and the majority (60.15\%), of the respondents had heard about Buruli ulcer in their communities; $25.9 \%$ of the respondents said they either saw some of the Buruli ulcer patients before infection or they had been infected before; another $6.3 \%$ said they heard about Buruli ulcer from media reports and discussions while $4.6 \%$ said they heard about it from the hospital (Table 2).

\section{Community Ideas about Buruli Ulcer Infection}

Respondents were asked whether they know of any Buruli ulcer infected person 
in their communities before the data collection for the present study and the majority $(85 \%)$ responded in the affirmative. With regards to the signs and symptoms of Buruli ulcer infection, $74.3 \%$ of the respondents said painless itchy boils were associated with the early signs and symptoms while $16.7 \%$ mentioned rashes as signs of infection.

Two main causes of Buruli ulcer were reported by respondents; natural causes (77.6\%) and supernatural causes (60.1\%). However, $39.5 \%$ of them mentioned both the natural and supernatural causes. There was a significant difference between males (36\%) and females (69\%) with females more likely to report natural causes of Buruli ulcer than males $(p=0.006)$. In terms of level of education and the attribution of the cause of Buruli ulcer infection, there was a significant difference between respondents with no education and those with at least primary education. Significantly more respondents with at least primary education (45.6\%) were more likely to report that Buruli ulcer is caused by both natural and supernatural causes than those with no education $(28.85)(p<0.001)$. Moreover, those with at least primary education (34.7\%) were more likely to report only natural causes than those with no education $(p=0.034)$.

\section{Community Perceptions about Buruli Ulcer Wounds}

Various causes of wounds were reported by respondents. These were; cuts 59\%, accidents-both domestic and motor (55.3\%), falling $(21.3 \%)$ and bites from insects $(17.7 \%)$ among others. Asked how wounds are categorised in the communities, majority (39.7\%) of the respondents said wounds are categorised according to natural (ordinary) and supernatural (bewitched/cursed) causes, 27\% said wounds are categorised according to how serious they are, thus more serious or severe wounds that are not healing fast, were attributed to supernatural causes. Also, $17.3 \%$ said the categorisation is based on the way the wound looks like, thus, wounds that look horribly bad and smell offensive were attributed to supernatural causes. According to respondents, wound categorisation helps to know how to manage/treat a particular wound.

Respondents were asked to describe the kind of wounds they would call Buruli ulcer in their communities. The Majority, (61\%) described Buruli ulcers as wounds that do not heal fast/quickly or at all, while $28 \%$ described Buruli ulcers wound as cotton wool wounds. Respondents also gave two main reasons why they thought Buruli ulcer wounds are different from other wounds. While $50 \%$ of the respondents said the difference is that Buruli ulcer wounds do not heal fast and smell bad compared to other wounds, $42 \%$ said the difference is that Buruli ulcer wounds have cotton wool-like (necrotic tissue) edges which other wounds do not have.

\section{Community Perceptions and Reactions towards Buruli Ulcer Patients}

Buruli ulcer patients were perceived as people who have been bewitched (36.7\%). 
Others (21\%) blamed them as people who did not take good care of themselves while another $11.1 \%$ saw Buruli ulcer infected people as having normal wounds. Interestingly, while $7 \%$ of the respondents saw Buruli ulcer patients as witches and wizards, $6 \%$ saw them as ordinary sick people in the community. There was no gender difference in the way Buruli ulcer patients were perceived in the study area. However, respondents in the age group 41 and above years, (60\%) were more likely to perceive Buruli ulcer infected people as having been bewitched compare to those aged 10 - 40 years $(p=0.004)$. On the other hand, respondents aged 10 - 40 years (10.7\%) were more likely to see Buruli ulcer infected persons as witches and wizards than those aged 41 and above years (3.8\%). There was no difference between the educated and non-educated in terms of how they perceive Buruli ulcer patients in the study area.

Various reactions towards Buruli ulcer patients were reported by respondents. Findings revealed that Buruli ulcer infection does not evoke sympathy from some members of the community as; $30.1 \%$ of the respondents said they would stay away from a Buruli ulcer infected person, $25.5 \%$ said they would react in a normal way towards Buruli ulcer patients but with caution, while $19.2 \%$ said they would get closer to Buruli ulcer infected person without hesitations.

Asked whether they would interact with Buruli ulcer infected persons in terms of building relationships, similar proportions of respondents said they would (49\%) and they will not (48\%). However, when it comes to its infectiousness, $59.7 \%$ of the respondents said Buruli ulcer is infectious, thus could be transmitted from one person to the other with $33.7 \%$ insisting that it is not infectious, thus could not be transmitted from one person to the other, while $6.6 \%$ said they did not know whether Buruli ulcer is infectious or not.

Out of the 300 respondents, $91.3 \%$ said Buruli ulcer is a major health problem in the study area. This position was supported by various reasons including the fact that the mode of transmission of Buruli ulcer is not known, there is no definite means of preventing the infection and the disease mostly affects children in the study area. However, a minority (7.7\%) of the respondents said Buruli ulcer is no longer a major health problem in the study area with the reason that it is not common these days because of the educational interventions going on in the sub-district.

On the question of whether Buruli ulcer is curable or not, $78.3 \%$ said the disease is curable while $16.3 \%$ said it is not. For those who said Buruli ulcer was curable, $41 \%$ said it can be cured through biomedical treatment, $19.3 \%$ said it can be cured by traditional practitioners and $18 \%$ said it can be cured using both biomedical and traditional treatments. For the respondents who said Buruli ulcer is not curable, $7.3 \%$ of them said it is so because it is a disease brought about by being cursed, $6.7 \%$ said it is so because the disease is caused by spiritual means and $2.3 \%$ said they did not know why it could not be cured. It is important to note that there is no relationship between socio-demographic characteristics and community perceptions on the curability of Buruli ulcer. 


\section{Community Views on Buruli Ulcer Prevention}

Table 3 summarised the community views on how to prevent Buruli ulcer in the study area. Respondents' views on prevention were clearly rooted in their belief on the causes of Buruli ulcer disease, which could be classified as natural and/or supernatural. In line with these perceived causes, various preventive measures of Buruli ulcer were reported and prominent among them were by "good living/eating well" $(108,36.0 \%)$, "clean environment $(83,27.7 \%)$ and not offending evil people and gods $(60,20.0 \%)$ (Table 3$)$.

\section{Discussion}

Finding of the study revealed that an overwhelming majority of the respondents in Ga South Municipality were knowledgeable about Buruli ulcer disease and its presentations. The high level of knowledge about Buruli ulcer by community respondents corroborated an earlier study in Ghana which reported a high prevalence in the study district which was more than four times the national average (Amofah et al., 2002). This is consistent with earlier findings reported from the study area (Amofah et al., 2002; Asiedu \& Etuaful, 1998; Kargbo-labour, 2010). The extensive knowledge of respondents is also demonstrated in their awareness of early signs and symptoms of the disease, which was reported as either a painless itch or boils or rashes. These are consistent with biomedical knowledge (Portaels et al., 2009; Elliott, 2010; Nienhuis et al., 2010). These findings could serve as entry points for educational messages targeting early reporting to the health facility for diagnosis and treatment. These findings were however different from earlier work done by Renzaho et al. (2007) in the Ga West district where they reported that community members had very poor understanding of the aetiology of the disease, although the disease itself was well known. However, the change in community members understanding should be seen in light of continuous interactions between formal health systems and communities in terms of case searching and reporting over time. As early case detection, diagnosis and treatment spread across the endemic communities, the people have become more familiar with the early signs and symptoms of the disease (Ahorlu et al., 2013; Ahorlu et al., 2014).

Table 3. Community views on Buruli ulcer prevention.

\begin{tabular}{cc}
\hline Characteristics & Frequency (\%) \\
$\mathbf{N}=\mathbf{3 0 0}(\mathbf{1 0 0 \% )}$
\end{tabular}


The local names for the disease revealed the depth of local meanings and interpretations of Buruli ulcer disease in the study communities. For example, the Ga people call the disease "Odontihela", the Ewe call it "Detsifudor" and the Akan call it "Asawakuro", and all these could be translated to mean "cotton wool disease". The Ewe call a chronic wound "abimakumaku" meaning a never healing wound whiles the Akan call it "kisikuro" to mean the same thing. The Ga call it "helagbonyo" meaning a bad wound. This finding is similar to what Winch et al. (1996) found in Tanzania where local names were used to classify routine or mild malaria fevers. They reported that the term most commonly used to translate the word malaria was "homaya malaria" or malaria fever, and for residents of the study area in Tanzania, it was an illness closely associated in people's minds with formal health services. According to Marx (1989) in social and epidemiological research, social factors remain largely understudied and poorly understood. He postulated that in order to diagnose, treat and control a disease effectively, a wide range of factors such as culture (local languages), behaviour, environment and economics should be taken into consideration. In this direction, the local names for Buruli ulcer disease, as revealed in this study would help to understand public health issues of diagnosis, prevalence, interventions and management/treatment in order to effectively control Buruli ulcer in the Ga South Municipality.

Two main factors identified as influencing the causes of Buruli ulcer disease were natural and supernatural. They could either independently or concurrently cause Buruli ulcers. For instance, a bite from an insect, which is a natural cause, could equally be interpreted as a supernatural cause because of the belief that, a witch/wizard, spirit and gods could transform themselves into insects and infect an individual with Buruli ulcer. Findings therefore show that although there is a high knowledge of signs and symptoms of Buruli ulcer among community members in the Obom sub-district, their understandings and interpretations of its causative factors varied from those of the biomedical understandings. It has been reported from Benin that treatment-seeking behaviour can be related to a patient's perception as to the cause of the illness (Aujoulat et al., 2003). Attending hospital is associated with illnesses that are perceived to be caused by natural factors while illnesses that are perceived to have been induced by sorcery need to be addressed by a traditional healer to counteract the sorcery (Aujoulat et al., 2003). The implication of this is that people would delay treatment for the disease in biomedical health facilities by resorting to self and traditional options of treatment. This presents a serious public health concern because when Buruli ulcer advances to a category three stage, it eventually leads to chronic sores and serious deformities leading to disabilities. At category three stages, treatment becomes very costly thereby putting a heavy financial burden on families, health facilities and the nation as a whole. Consequently, the belief that Buruli ulcer is caused by both natural and supernatural factors might be one of the factors influencing the choice of self-medication and traditional treatment. This strongly 
supports an earlier study conducted in Cameroun where researchers termed this as double causality; implying illness having both natural and mystical derivations (Grietens et al., 2012).

Patients' therapeutic itineraries cannot be understood without insight into the mechanism of double causality, the interchangeability and frequent compatibility of the two treatment kinds, the dynamic nature of aetiological beliefs, and insight into decisive factors that impact treatment choice. Even though the implications on disease control are rarely taken into account, various studies have stressed the importance of double causality in relation to other diseases. Hausmann-Muela et al. (1998), showed how people in rural Tanzania were well aware that malaria was caused by parasites. However, they also claimed that these parasites could be mystically "hidden" during biomedical diagnosis, leading to possibly fatal delays in finding the appropriate treatment. Likewise, sorcery could produce "fake parasites", once more leading to erroneous diagnosis delayed treatment. Similarly, in the South-African context, Thomas (2008) explained that, while biomedical narratives on HIV provided information on the virus and how it developed, they did not provide people with an explanation of why they became infected in the first place. Thomas (2008) claimed that this double causal layer was essential in understanding people's perception of the illness and, consequently, their perception and response to HIV-treatment.

Although findings from Grietens et al. (2012), strongly support some earlier studies by Hausmann-Muela et al. (1998) and Thomas (2008), it is at variance with Stienstra et al. (2002) who attributed the cause of Buruli ulcers to only supernatural factors particularly the working of witchcrafts. This study has reinforced the fact that even though formal education broadens ones' scope and leads to a change in world view, the socio-cultural background and environment have a great influence on people's understanding and their interpretations of issues. Thus, respondents who had formal education are more likely to attribute the cause of Buruli ulcer to both natural and supernatural factors. The implication of believing that Buruli ulcer is caused by both natural and supernatural factors may have public health ramifications as it may affect treatment seeking behaviour of the people. This could affect early case detection and treatment, depending on the dominant attributions made regarding perceived causes. It also confirms the assertion that education and/or a profession do not divorce one from one's cultural orientation (Louw \& Pretorius, 1995; Pretorius, 1991; Wessels, 1985; Karim et al., 2007).

In a nutshell, this study shows that the perceived origins of Buruli ulcers often had both natural and mystical causal layers simultaneously. For instance, though respondents often believed that they were infected with Buruli ulcer by an insect bite, many of them also stated that this insect was intentionally sent to them through sorcery. As such, efforts at disseminating biomedical explanations for Buruli ulcer, as outlined in health education messages, can negatively affect treatment seeking and delay treatment; but this is not necessarily the case since 
additional mystical elements can be present in natural aetiologies (Grietens et al., 2012).

According to Portaels et al. (2001), a combination of various occurrences and experiences, whether natural or spiritual help in shaping the perception of each individual and also define its cultural milieu. Culture, therefore, is the lens through which individuals perceive, relate and react to various phenomena including health (Wessels, 1985). Various concepts of explanations are given by people in different cultures, to describe or explain illness. These explanatory models are congruent with the way people perceive illness, which are derived from concepts, symbols, beliefs and practices that have deep roots in their culture (Bannerman et al., 1983; Portaels et al., 2001). Findings from the study revealed that experiences, occurrences and beliefs rooted in culture lead to the categorisation of wounds in line with perceived causes, natural (naturalistic) and supernatural (personalistic). The position of the people is that wound categorisation helps them to know how to manage/treat or cure a particular wound based on it causes, be it natural or supernatural. As found by Grietens et al. (2012), the prolonged nature of the illness and treatment, the difficulty of the healing process and recidivism can lead to assumptions about possible mystical involvement even for sufferers who were convinced of the natural origin of their illness at the onset of symptoms. These experiences therefore might influence the perceptions of respondents at the Obom sub-district in believing that Buruli ulcer is caused by supernatural forces. An important distinction that shaped the perceptions of respondents about Buruli ulcers from other wounds was its clinical manifestation and the prolonged period of healing.

Buruli ulcers were distinctively described as having cotton wool (odonti, detsifu and asawa) in it and do not heal fast or at all. These community explanations though local, are synonymous to scientific and microbiological explanations of Buruli ulcer as having necrotic tissue and take a long time to heal if delayed for treatment (Van der Werf et al., 1989; Eddyani et al., 2009; Nienhuis et al., 2010). The necrotic tissue is what the local people refer to as cotton wool. Findings from the study also reveal that there are varied perceptions about $\mathrm{Bu}$ ruli ulcer patients. While a greater proportion of respondents perceive Buruli ulcer patients as people who have been bewitched, an appreciable proportion of them see the patients as people who did not take good care of themselves. These findings contradict the report that Buruli ulcer patients in Ghana were solely perceived in their communities as being witches/wizards or bewitched (Stienstra et al., 2002). This points to the fact that the on-going community education programmes in endemic communities are making some positive impact on the perception of the people and must be continued (Ahorlu et al., 2013).

The study showed that, the condition of the infected persons does not evoke sympathy from some respondents as most of them would stay away from a $\mathrm{Bu}$ ruli ulcer infected person and even those who will interact with the patients said they would do so with caution. These findings are similar to what Renzaho et al. 
(2007) reported from Ghana, where more than a third of respondents stated explicitly that they would not accept a Buruli ulcer patient as a community leader, though they would interact with them. These kinds of attitude toward the patients may affect treatment seeking behaviour as people with the disease may be tempted to conceal their condition from the larger community to avoid discrimination against them. This also reinforces the need for continuous health education on Buruli ulcer in endemic communities in Ghana so as to demystify it and reduce negative reactions towards the infected and the affected persons (WHO, 2001; Ackumey et al., 2011).

Findings from the study show that most respondents would resort to self-medication or visit the drug store whenever, they are not well. This is similar to Nsungwa-Sabiiti et al. (2004) findings on malaria in Uganda where self-medication was used as a first treatment option when signs and symptoms of malaria were detected. The majority said the drug store was the most accessible health service delivery point to them. These findings were consistent with similar work done by Grietens et al. (2012) in Cameroun where it was found that many respondents resorted to self-medication or visited the drug store when unwell. Moreover, Kibadi et al. (2009) conducted a study in rural Democratic Republic of Congo on Buruli ulcer patients and also found that patients waited for an average of two months (wait and see period) after noticing their Buruli ulcer status during which they used their social network to confirm the disease. They resorted to self-medication and this was usually with allopathic drugs in the form of non-specific antibiotics and anti-inflammatory medicaments mostly without prescription. These drugs were normally purchased from local markets, and they dressed the wound with local cloth or bandage. Another option was the use of the health facility. Moreover, findings in this study were similar to what Lönnroth, et al. (2001), found in their TB research in Vietnam, where patients resorted to self-care and delayed treatment for TB in biomedical health facilities due to the fear of being stigmatised. As with Buruli ulcer, TB represents a classic public health issue that affects the whole society and therefore has received Governmental attention in its appropriate and effective detection, diagnosis and treatment (Lönnroth et al., 2001). Nonetheless, studies of health seeking behaviour in relation to TB repeatedly demonstrate that patients do not always choose a public health care facility for the entire duration of treatment; they delay diagnosis and often do not complete the lengthy course of treatment necessary for effective healing (Steen \& Mazonde, 1999; Yeboah-Manu et al., 2013).

Steen and Mazonde (1999) found that $95 \%$ of TB patients in Botswana visited a "modern" health facility as a first step but went on further to visit a traditional or faith healer as well after initiating modern treatment. The reasons given by most of the respondents were that the herbs to use for treatment and the drug stores are closer to them and therefore very convenient to access. This confirmed the findings of earlier studies that treatment within or outside of the Buruli ulcer patients' community was one of the decisive factors in determining treatment 
choice (Adamba \& Owus, 2011; Grietens et al., 2012). In this study, most of the respondents said health facilities available to them are very far. In fact, some of the respondents state that it is less burdensome, socially and financially, to access treatment at the drug store instead of walking long distances for treatment in a health facility. Findings in this study supported the claim made by Ahorlu et al. (2013) and Adamba \& Owus (2011) that treatment outside of the community, whether biomedical or traditional, usually placed an overwhelming financial and social burden on the patient and his/her household as it either implied constant travelling to receive treatment or social isolation for the patient who was required to stay without relatives at the place of treatment. These movements also lead to social isolation for the patient who is required to stay without relatives at the place of treatment to save money on travel cost (Grietens et al., 2012). Contrary to the reasons cited in this study for treatment choices resorted to by Buruli ulcer patients, Awusabo-Asare and Anarfi (1997), in their HIV study reported that due to the social interpretations given to certain diseases, persons affected tend to avoid other people, as they may initially choose home or self-administered treatment strategies mostly involving the use of herbs, self-medication, and purchase of drugs over the counter. This tendency leads to delays in reporting the infection for early attention, thus enlarging the enormity of coping that is required. The health implications of self-medication and patronising the drug stores are serious for the individual and the society at large. This might lead to misuse and abuse of drugs, especially antibiotics by the patient, since most of the store attendants are not professionals who could give the right dose to their clients. However, involving drug store attendants, in management, health promotion programmes and training them on pharmaceutical usage by the Ghana Health Service through the control programme could help regulate and promote appropriate use of drug stores by people infected with Buruli ulcer.

Findings of this study about community views on Buruli ulcer prevention fit into what Seijas (1973), described as the personalistic and naturalistic views in disease aetiology. A personalistic system is one in which illness is believed to be caused by the active, purposeful intervention of a sensate agent who may be a supernatural being, a nonhuman being, or a human being. The sick person is a victim, the object of aggression or punishment directed specifically against him/her, for reasons that concern him alone. Thus in this study, those who hold personalistic views about the causes of Buruli ulcer disease give suggestions such as people obeying their gods or not offending other people as a means of preventing Buruli ulcer infection. However, in naturalistic systems illness is explained in impersonal, systemic terms that conform above all to an equilibrium model; health prevails when the insensate elements in the body, the heat, the cold, the humors are inbalance appropriately to the age and condition of the individual in his/her natural and social environment (Seijas, 1973). Thus those who hold naturalistic views about the causes of Buruli ulcer also give suggestions such as living in a clean environment or maintaining a good hygiene as a means to prevent Buruli ulcer infection in the community. 
Similar to what was reported in this study, Grietens et al. (2012) maintained that the two clearly distinct perceived origins of the disease (natural and mystical aetiologies) are often used interchangeably or linked together. This is also consistent with Steen and Mazonde's (1999) found in their TB study in Botswana where natural and mystical views were reported as measures for preventing TB infection. According to Nurge (1977), in Tzintzuntzan, and many other Latin American communities, "the prudent person doesn't stand on a cold floor in bare feet", "doesn't wash hands after whitewashing a wall”, "doesn't go out into the night air immediately after using the eyes". In theory, at least, a hyper cautious individual should be able to avoid almost all illness by not doing or doing certain things as suggested by the community members in our study.

On the other hand, the supernatural or mystical community views about $\mathrm{Bu}$ ruli ulcer prevention represent the personalistic systems where the basic personal health strategy seems to emphasise the "dos," and especially the need to make sure that one's social networks with fellow human beings, with ancestors, and with deities, are maintained in good working order (Seijas, 1973). Although this means avoiding those acts known to arouse resentment, "don'ts", it particularly means careful attention being paid to the propitiatory rituals that are a god's due, to positively demonstrate to ancestors that they have not been forgotten, and to friendly acts to neighbours and fellow community members that remind them that their good will is valued. In short, recognising major overlapping, the primary strategies to maintain health in the two systems are significantly different. Both require thought. But in the personalistic structure, time and money are essential ingredients in the maintenance of health. In the other, the naturalistic, knowledge of how the system works, and the will to live according to its dictates, is the essential thing; this costs very little, in either time or money (Seijas, 1973). This analysis by Seijas (1973) is consistent with the findings of this study on the control and prevention of Buruli ulcer in Ghana.

\section{Conclusion}

This study concludes that misconceptions and community beliefs and practices could be impediments to the management and control of Buruli ulcers in endemic communities of Ghana. Findings in this study reinforced the need for sustained community education on Buruli ulcer to ensure early case detection, management and control in the endemic regions of Ghana. Otherwise, delayed treatment could lead to a high cost of treatment and long durations of treatment in some cases. Consequently, this would result in deformities and disabilities among Buruli ulcer patients.

\section{Limitation of the Study}

The main weakness of this study was that, even though it was conducted in more than one community, all the communities are in (one sub-district) Obom sub-district. For this reason, findings from the study could not be generalised 
beyond the study area, though most of the health system issues may be applicable countrywide. Caution needs to be exercised when making inferences from the study in other contexts in and out of Ghana.

\section{Author's Contribution}

At the conception, design and implementation, and data collection stages of this paper, EK was involved. After the collection of the data, EK did the analysis, and wrote the paper, proofread and finalised it.

\section{Acknowledgements}

I sincerely thank the chiefs and people as well as the respondents of the study communities for their support. This study was one of my PhD chapters and I sincerely thank my supervisors: Professors Dorothy Yeboah-Manu, Philip Baba Adongo and Collins S. Ahorlu for their excellent supervision and support. I also thank my research assistant, Mr Daniel Okyere for his assistance. Financial support for this research was provided by the Optimus Foundation, UBS through the Stop Buruli consortium. I thank Professor Mark Nichter for the support. I sincerely thank the staff of Obom health centre for their collaborations. Mr Isaac Lamptey and Seth Baffoe deserve special mention for leading the research team.

\section{Conflicts of Interest}

The author hereby declares that he has no conflict of interest.

\section{References}

Ackumey, M. M., Kwakye-Maclean, C., Ampadu, E. O., de Savigny, D., \& Weiss, M. G. (2011). Health Services for Buruli Ulcer Control: Lessons from a Field Study in Ghana. PLoS Neglected Tropical Diseases, 5, e1187. https://doi.org/10.1371/journal.pntd.0001187

Adamba, C., \& Owus, A. Y. (2011). Burden of Buruli Ulcer: How Affected Households in a Ghanaian District Cope. African Study Monographs, 32, 1-23.

Ahorlu, C. K., Koka, E., \& Yeboah-Manu, D. (2014). Social Interventions for Buruli Ulcer Control in Obom Sub-District of Ghana. Towards Effective Disease Control in Ghana: Research and Policy Implications: Volume 2 Other Infectious Diseases and Health Systems, $2,5$.

Ahorlu, C. K., Koka, E., Yeboah-Manu, D., Lamptey, I., \& Ampadu, E. (2013). Enhancing Buruli Ulcer Control in Ghana through Social Interventions: A Case Study from the Obom Sub-District. BMC Public Health, 13, 59. https://doi.org/10.1186/1471-2458-13-59

Amofah, G., Bonsu, F., Tetteh, C., Okrah, J., Asamoa, K., Asiedu, K., \& Addy, J. (2002). Buruli Ulcer in Ghana: Results of a National Case Search. Emerging Infectious Diseases, 8, 167-170. https://doi.org/10.3201/eid0802.010119

Asiedu, K., \& Etuaful, S. (1998). Socioeconomic Implications of Buruli Ulcer in Ghana: A Three-Year Review. The American Journal of Tropical Medicine and Hygiene, 59, 1015-1022. https://doi.org/10.4269/ajtmh.1998.59.1015

Aujoulat, I., Johnson, C., Zinsou, C., Guédénon, A., \& Portaels, F. (2003). Psychosocial 
Aspects of Health Seeking Behaviours of Patients with Buruli Ulcer in Southern Benin. Tropical Medicine \& International Health, 8, 750-759. https://doi.org/10.1046/j.1365-3156.2003.01089.x

Awusabo-Asare, K., \& Anarfi, J. K. (1997). Health-Seeking Behaviour of Persons with HIV/AIDS in Ghana. Health Transition Review, 7, 243-256.

Bannerman, R. H., Burton, J., \& Ch'en, W. C. (1983). Traditional Medicine and Health Care Coverage: A Reader for Health Administrators and Practitioners. http://www.cabdirect.org/abstracts/19842007666.html

Eddyani, M., Fraga, A. G., Schmitt, F., Uwizeye, C., Fissette, K., \& Johnson, C. (2009). Fine-Needle Aspiration, an Efficient Sampling Technique for Bacteriological Diagnosis of Nonulcerative Buruli Ulcer. Journal of Clinical Microbiology, 47, 1700-1704.

https://doi.org/10.1128/JCM.00197-09

Elliott, C. (2010). The Effects of Silver Dressings on Chronic and Burns Wound Healing. British Journal of Nursing, 19, S32-S36.

Ghana Statistical Service. (2010). Population and Housing Census.

Grietens, K. P., Toomer, E., Boock, A. U., Hausmann-Muela, S., Peeters, H., Kanobana, K., \& Ribera, J. M. (2012). What Role Do Traditional Beliefs Play in Treatment Seeking and Delay for Buruli Ulcer Disease? Insights from a Mixed Methods Study in Cameroon. PLoS ONE, 7, e36954.

Hausmann-Muela, S, Muela Ribera, J., \& Tanner, M. (1998). Fake Malaria and Hidden Parasites-The Ambiguity of Malaria. Anthropology and Medicine, 5, 43-61.

Kargbo-Labour, I. J. (2010). Community Perception and Knowledge of Buruli Ulcer in the Ga West Municipality Area. Ghana: University of Ghana. http://ugspace.ug.edu.gh/handle/123456789/5155

Karim, F., Islam, M. A., Chowdhury, A. M. R., Johansson, E., \& Diwan, V. K. (2007). Gender Differences in Delays in Diagnosis and Treatment of Tuberculosis. Health Policy and Planning, 22, 329-334. https://doi.org/10.1093/heapol/czm026

Kibadi, K., Boelaert, M., Kayinua, M., Minuku, J.-B., Muyembe-Tamfum, J.-J., Portaels, F., \& Lefevre, P. (2009). Therapeutic Itineraries of Patients with Ulcerated Forms of Mycobacterium ulcerans (Buruli Ulcer) Disease in a Rural Health Zone in the Democratic Republic of Congo. Tropical Medicine \& International Health, 14, 1110-1116. https://doi.org/10.1111/j.1365-3156.2009.02324.x

Koka, E., Yeboah-Manu, D., Okyere, D., Adongo, P. B., \& Ahorlu, C. K. (2016). Cultural Understanding of Wounds, Buruli Ulcers and Their Management at the Obom Sub-District of the Ga South Municipality of the Greater Accra Region of Ghana. PLoS Neglected Tropical Diseases, 10, No. 7. https://doi.org/10.1371/journal.pntd.0004825

Lönnroth, K., Linh, P. D., \& Diwan, V. K. (2001). Utilization of Private and Public Health-Care Providers for Tuberculosis Symptoms in Ho Chi Minh City, Vietnam. Health Policy and Planning, 16, 47-54. https://doi.org/10.1093/heapol/16.1.47

Louw, D. A., \& Pretorius, E. (1995). The Traditional Healer in a Multicultural Society: The South African Experience. In L. L. Adler, \& B. R. Mukherji (Eds.), Spirit versus Scalpel: Traditional Healing and Modern Psychotherapy (pp. 41-58). London: Bergin and Garrey.

Marx, R. (1989). Social Factors and Trachoma: A Review of the Literature. Social Science \& Medicine, 29, 23-24. https://doi.org/10.1016/0277-9536(89)90124-X

Ministry of Health, MoH, Ghana. (2012). Half-Year Report.

Nienhuis, W. A., Stienstra, Y., Thompson, W. A., Awuah, P. C., Abass, K. M., \& Tuah, W. (2010). Antimicrobial Treatment for Early, Limited Mycobacterium ulcerans Infection: 
A Randomised Controlled Trial. The Lancet, 375, 664-672. https://doi.org/10.1016/S0140-6736(09)61962-0

Nsungwa-Sabiiti, J., Källander, K., Nsabagasani, X., Namusisi, K., Pariyo, G., Johansson, A., Tomson, G., \& Peterson, S. (2004). Local Fever Illness Classifications: Implications for Home Management of Malaria Strategies. Tropical Medicine \& International Health, 9, 1191-1199. https://doi.org/10.1111/j.1365-3156.2004.01319.x

Nurge, E. (1977). Etiology of Illness in Guinhangdan. In D. Landy (Ed.), Culture, Diseases and Healing: Studies in Medical Anthropology (pp. 138-146). New York, NY: Macmillan Publishing Inc.

Paul, F. (1999). Infections and Inequalities: The Modern Plagues. Berkeley, CA: University of California Press.

Portaels, F., Chemlal, K., Elsen, P., Johnson, P. D., Hayman, J. A., Hibble, J., \& Meyers, W. M. (2001). Mycobacterium ulcerans in Wild Animals. Revue Scientifiqueet Technique (International Office of Epizootics), 20, 252.

Portaels, F., Silva, M. T., \& Meyers, W. M. (2009). Buruli Ulcer. Clinics in Dermatology, 27, 291-305. https://doi.org/10.1016/j.clindermatol.2008.09.021

Pretorius, E. (1991). Traditional and Modern Medicine Working in Tandem. Curationis, 14, 10-13. https://doi.org/10.4102/curationis.v14i4.339

Renzaho, A., Woods, P. V., Ackumey, M. M., Harvey, S. K., \& Kotin, J. (2007). Community-Based Study on Knowledge, Attitude and Practice on the Mode of Transmission, Prevention and Treatment of the Buruli Ulcer in Ga West District, Ghana. Tropical Medicine \& International Health, 12, 445-458.

https://doi.org/10.1111/j.1365-3156.2006.01795.x

Seijas, H. (1973). An Approach to the Study of Medical Aspects of Culture Current Anthropology (Vol. 14, pp. 544-545).

Steen, T. W., \& Mazonde, G. N. (1999). Ngaka ya setswana, ngaka ya sekgoa or both? Health Seeking Behaviour in Batswana with Pulmonary Tuberculosis. Social Science \& Medicine, 48, 163-172. https://doi.org/10.1016/S0277-9536(98)00329-3

Stienstra, Y., van der Graaf, W. T., Asamoa, K., \& van der Werf, T. S. (2002). Beliefs and Attitudes toward Buruli Ulcer in Ghana. The American Journal of Tropical Medicine and Hygiene, 67, 207-213. https://doi.org/10.4269/ajtmh.2002.67.207

Thomas, F. (2008). Indigenous Narratives of HIV-AIDS: Morality and Blame in a Time of Change. Medical Anthropology, 27, 227-256.

Van der Werf, T. S., van der Graaf, W. T., Groothuis, D. G., \& Knell, A. J. (1989). Mycobacterium Ulcerans Infection in Ashanti Region, Ghana. Transactions of the Royal Society of Tropical Medicine and Hygiene, 83, 410-413. https://doi.org/10.1016/0035-9203(89)90521-X

Wessels, W. H. (1985). Understanding Culture-Specific Syndromes in South Africa-The Western Dilemma. Modern Medicine of South Africa, 10, 51-63.

Winch, P. J., Makemba, A. M., Kamazima, S. R. et al. (1996). Local Terminology for Febrile Illnesses in Bagamoyo District, Tanzania and Its Impact on the Design of a Community-Based Malaria Control Programme. Social Science \& Medicine, 42, $1057-1067$. https://doi.org/10.1016/0277-9536(95)00293-6

World Health Organization, WHO. (2000). Buruli Ulcer: Mycobacterium ulcerans Infection. World Health Organization.

World Health Organization, WHO. (2001). Buruli Ulcer: Fact Sheet No. 199. Geneva: WHO. 
World Health Organization, WHO. (2009). Neglected Tropical Diseases, Hidden Successes, Emerging Opportunities. http://apps.who.int/iris/handle/10665/44214

Yeboah-Manu, D., Kpeli, G. S., Ruf, M.-T., Asan-Ampah, K., Quenin-Fosu, K., \& Owusu-Mireku, E. (2013). Secondary Bacterial Infections of Buruli Ulcer Lesions before and after Chemotherapy with Streptomycin and Rifampicin. PLoS Neglected Tropical Diseases, 7, e2191. https://doi.org/10.1371/journal.pntd.0002191 


\section{Appendix}

\section{Interviewer:}

This interview is to help us to better understand the Community Knowledge and Perceptions about Buruli Ulcers in Obom sub-district of the Ga South Municipality in the Greater Accra Region of Ghana. Your participation in the study is completely voluntary. We will also like to assure you that all information collected in the course of the study will remain confidential.

Ask for oral consent

Thank you for your participation. In case you have any questions, please let us know.

Please also ask when you have a problem understanding a question.

\begin{tabular}{|c|c|c|c|}
\hline Q. No & Questions & Response & Code \\
\hline 1 & Interviewer number: & & \\
\hline 2 & Community name & & \\
\hline 3 & Sub-district & $\ldots$ & \\
\hline 4 & District & & \\
\hline \multirow{2}{*}{5} & \multirow{2}{*}{ Sex of respondent } & 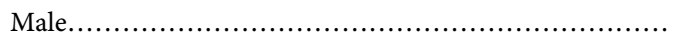 & 1 \\
\hline & & Female................ & 2 \\
\hline \multirow{6}{*}{6} & \multirow{6}{*}{ Age } & 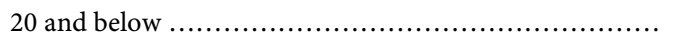 & 1 \\
\hline & & 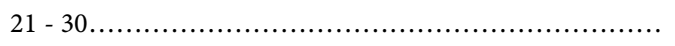 & 2 \\
\hline & & 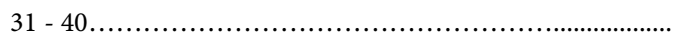 & 3 \\
\hline & & 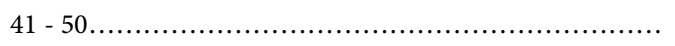 & 4 \\
\hline & & $51-60 \ldots \ldots \ldots \ldots \ldots \ldots \ldots \ldots \ldots \ldots \ldots$ & 5 \\
\hline & & 61 and above..................... & 6 \\
\hline \multirow{6}{*}{7} & \multirow{6}{*}{ Education } & 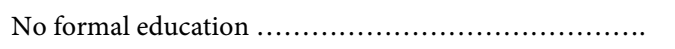 & 1 \\
\hline & & 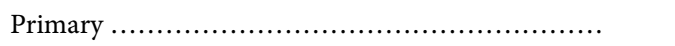 & 2 \\
\hline & & JHS (1) & 3 \\
\hline & & SHS … & 4 \\
\hline & & 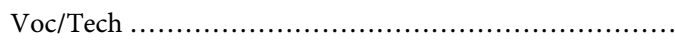 & 5 \\
\hline & & 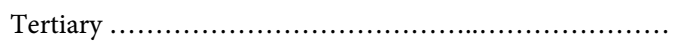 & 6 \\
\hline \multirow{4}{*}{8} & \multirow{4}{*}{ Ethnic Group } & 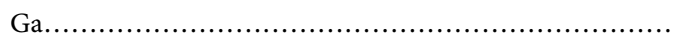 & 1 \\
\hline & & 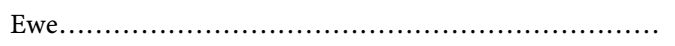 & 2 \\
\hline & & 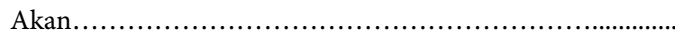 & 3 \\
\hline & & 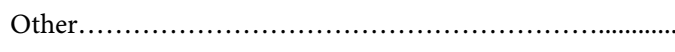 & 96 \\
\hline \multirow{5}{*}{9} & \multirow{5}{*}{ Religion } & 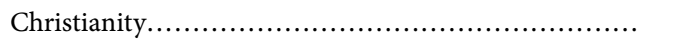 & 1 \\
\hline & & Islamic................................................... & 2 \\
\hline & & 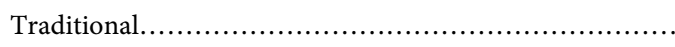 &. .3 \\
\hline & & 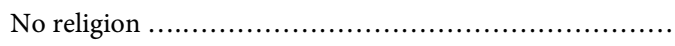 & 4 \\
\hline & & 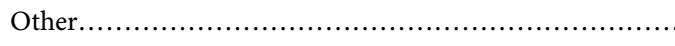 & .96 \\
\hline \multirow{7}{*}{10} & \multirow{7}{*}{ Main occupation } & 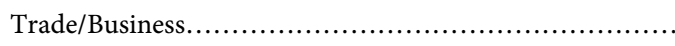 & 1 \\
\hline & & 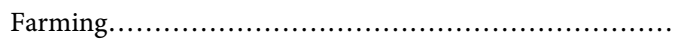 & .2 \\
\hline & & 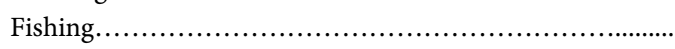 &. .3 \\
\hline & & Farming + Fishing &. .4 \\
\hline & & 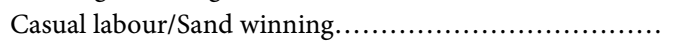 & 5 \\
\hline & & 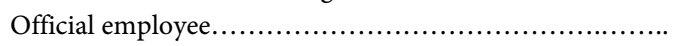 & 6 \\
\hline & & 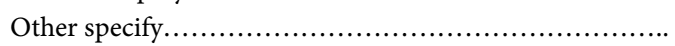 & 96 \\
\hline
\end{tabular}




\section{Continued}

\begin{tabular}{|c|c|c|}
\hline \multirow{5}{*}{11} & \multirow{5}{*}{ Relationship status } & (n) \\
\hline & & Married.... \\
\hline & & In a relationship but not married. \\
\hline & & Divorce/Separated... \\
\hline & & Widowed/widower... \\
\hline \multirow{5}{*}{12} & \multirow{5}{*}{$\begin{array}{l}\text { The first treatment resort } \\
\text { when not well }\end{array}$} & Self-medication ... \\
\hline & & Traditional healer/Spiritualist . \\
\hline & & Health facility . \\
\hline & & Church..... \\
\hline & & Other. \\
\hline
\end{tabular}

Basic Information

What are the commonest

Malaria.............................................. 1

Buruli ulcer ..................................... 2

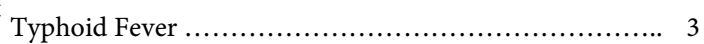

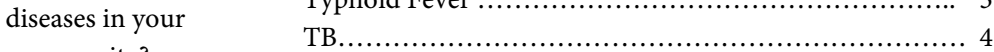

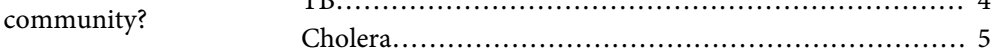

Other................................................ 96

How many health

14 facilities do you have in your community?

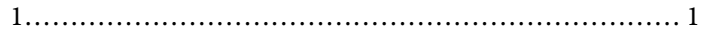

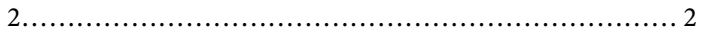

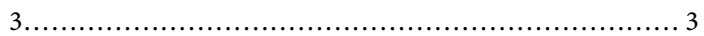

Other.............................................. 96

Clinic/hospital..................................... 1

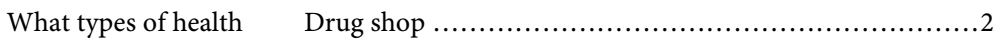

15 facilities are available to Traditional healer .......................................... 3

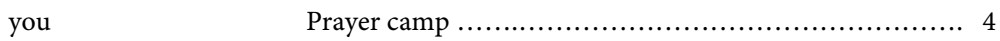

Other................................................... 96

Clinic/hospital...................................... 1

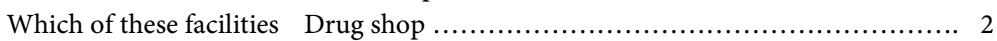

16 do you prefer to visit when you are not well

Traditional healer .................................. 3

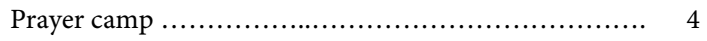

Other..................................................... 96

Very 1

How far is the nearest $\quad$ Far.................................................................... ${ }_{2}^{1}$

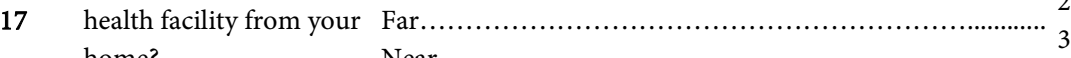

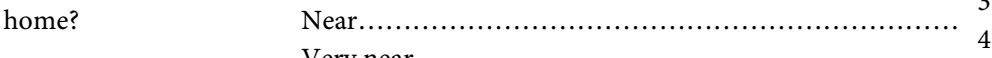

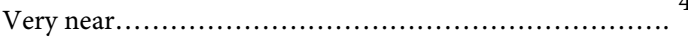

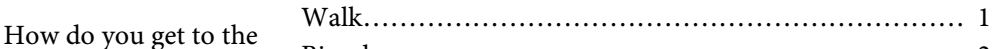

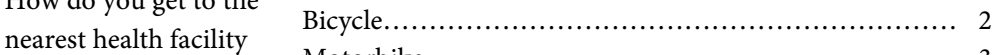

when you are not well? $\quad$ Motorbike............................................ 3

Car (private/taxi/trotro) ..............................4

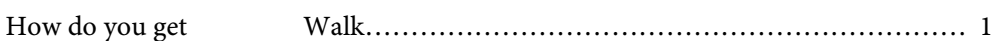

to the nearest $\quad$ Bicycle............................................... 2

herbalist/traditional Motorbike........................................ 3

healer when you get sick? Car (private/taxi/trotro) ............................... 4

\section{Knowledge of BU signs and symptoms}

Have you heard of the

disease that causes $\quad$ Yes...................................................

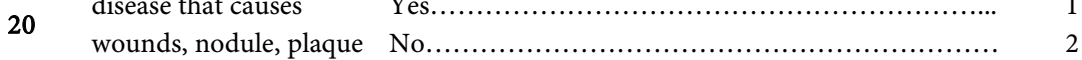

etc (Buruli ulcer)

21 What is its local name? 


\section{Continued}

22 If yes, how did you hear of the disease?

23 Why do you call it by that name?

Do you know anybody

24 who has been affected by the disease

No............

What signs and symptoms do you associate with a suspected case?

26

What in your opinion causes the disease?

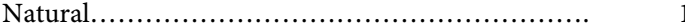

Supernatural.........................................

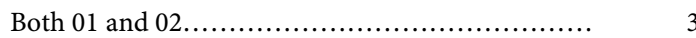

How do you react

27 towards anyone who suffers from the disease?

\section{Community Perceptions about BU}

Name possible ways in

28 which wounds come about

How are (types of)

29 wounds categorised in your community?

What are the bases for the

30 categorisation of wounds in your community?

What kinds of wounds

31 would you call Buruli ulcer? (local name)

How different are Buruli cer wounds from other wounds?

How does your community see people with $\mathrm{BU}$ wounds?

Would you interact with Yes

No...... from $\mathrm{BU}$ ?

Do you consider BU as an Yes.............................................. 1 infectious disease?

Don't Know................................................ 3

Do you regard $\mathrm{BU}$ as a health problem?

Yes. ...

No ........................................... 2

Don't Know.............................................. 3

Yes..................................................... 1

37 Is Buruli ulcer curable?

Don't Know........................................... 


\section{Continued}

If yes by what means

Traditional/spiritual means............................ 1

Biomedical means................................... 2

could it be cured?

Home/self means.................................... 3

Other specify........................................ 96

39

If no why could it not be

Spiritual disease...................................... 1

cured?

Cursed disease..................................... 2

Other specify..................................... 3

Health Seeking Behaviour for BU

Would you seek

treatment immediately Yes............................................. 1

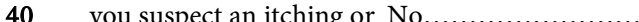

a boil on any part of your Don't Know............................................. 3

body?

41

How long would you wait to seek treatment?

Before one Month

Two to six Months.

After six months.

Self-medication

Which mode of treatmentTraditional/herbal/spiritual treatment. would you seek first?

Biomedical treatment

Other specify.....

Convenient to use.

Why would you prefer that choice (answer in $\mathrm{Q} 42)$ as a first option to others?

Close to place of residence.

Best place to manage condition

Less cost of treatment.

Other specify

Self-medication....

Which type of treatment Traditional/herbal/spiritual treatment. would you seek second?

Other specify

Would you combine one Yes.

or more types of treating No.

Buruli ulcer?

Don't Know....

Heal wound fast

If yes why would you do Meet spiritual and physical need. that?

Complement one another.

Other specify.

Delay wound healing.

If no why would you not

Cause infection....

Other specify.....

Self-medication/drug store.

Rank the following treatment options to Buruli ulcer in terms of preference Traditional/herbal/spiritual treatment.

Biomedical treatment

Other specify.....

9
9
1
3

